Special issue of the 3rd International Conference on Computational and Experimental Science and Engineering (ICCESEN 2016)

\title{
Investigation of Degradation of Electrical Properties after Thermal Oxidation of p-Type Cz-Silicon Wafers
}

\author{
M. MaOudj ${ }^{a, b, *}$, D. Bouhafs ${ }^{a}$, N. Bourouba ${ }^{b}$, N. Khelifati ${ }^{a}$, A. El Amrani $^{a}$, \\ R. BOUFNIK ${ }^{a}$ AND A. HAMIDA FERHAT ${ }^{b}$ \\ ${ }^{a}$ CRTSE, Technology Research Center of Semiconductors for the Energetics, \\ 02, Bd Frantz Fanon. BP 140 Alger 7 Merveilles, Algiers, Algeria \\ ${ }^{b}$ Ferhat Abbas University, Faculty of Technology, Department of Electronics, Setif, Algeria
}

\begin{abstract}
In this study we conducted thermal oxidation of Czochralski p-type $<100>$ silicon wafers. The oxidation was carried out at temperatures in the range of $850-1000{ }^{\circ} \mathrm{C}$, in a gas mixture of $\mathrm{N}_{2}: \mathrm{O}_{2}$, in order to deposit a thin layer $(10 \mathrm{~nm})$ of thermal silicon dioxide $\left(\mathrm{SiO}_{2}\right)$, generally used in the surface passivation of solar cells. The measurements of effective minority carriers lifetime $\tau_{\text {eff }}$ using the quasi-steady-state photoconductance have shown degradation of different samples after oxidation process. The calculation of surface recombination velocity after the oxidation process at different temperatures, gave the same value of $40 \mathrm{~cm} \mathrm{~s}^{-1}$, showing a low surface recombination velocity and, therefore, a good surface passivation. Finally, a study based on sample illumination technique, allowed us to conclude that our samples are dominated by bulk Shockley-Read-Hall recombination, caused by Fe-related centers, thereby causing the degradation of the lifetime of minority carriers.
\end{abstract}

DOI: 10.12693/APhysPolA.132.725

PACS/topics: 72.20.Jv, 81.16.Pr, 88.40.jj

\section{Introduction}

The reduction of recombination rates by the surface passivation of silicon wafers is a critical process for high efficiency solar cells. The thermal oxidation is among the methods used to passivate the silicon surface and the $\mathrm{SiO}_{2}$ has recently captured considerable attention of researchers in view of device applications [1]. It is well known that the silicon surface passivation using silicon dioxide $\left(\mathrm{SiO}_{2}\right)$ combines the field passivation effect, induced by fixed positive charges, and a dangling bond saturation, leading to low interface states density $D_{\text {it }}[2]$. High temperature $\left(900-1100{ }^{\circ} \mathrm{C}\right)$ thermal silicon dioxide has been used in solar cell process for many years, especially in high-efficiency solar cells, such as PERL (passivated emitter, rear locally diffused), PERT (passivated emitter, rear totally diffused), and PLUTO $[3,4]$. $\mathrm{SiO}_{2}$ film is usually formed by classical furnace oxidation or by rapid thermal oxidation. Classical furnace oxidation is generally used for passivation of laboratory highefficiency solar cells $[5,6]$.

However, in spite of this success, there are several problems associated with the passivation at a high temperature, because the high-temperature surface passivation schemes, degrade the bulk carrier lifetime of most crystalline silicon materials $[7,8]$, due to the activation of recombination centers.

Injection-dependent lifetime offers a convenient method to determine the defect parameters by fitting the injection-dependent lifetime with the Shockley-Read-Hall

*corresponding author; e-mail: maomo72@yahoo.fr
(SRH) model. In our work, we used this method to investigate some causes of thermal degradation in crystalline silicon materials.

\section{Experimental}

Boron-doped $<100>$ oriented Cz-silicon wafers with thickness of $320 \mu \mathrm{m}$ and $1-3 \Omega \mathrm{cm}$ resistivity were used in this study. The silicon wafers were cleaned following the piranha etching procedure, before the oxidation process.

A thin passivating layer of $10 \mathrm{~nm}$ of silicon dioxide was thermally grown in a quartz tube furnace at different temperatures $\left(850^{\circ} \mathrm{C}, 900^{\circ} \mathrm{C}, 950^{\circ} \mathrm{C}\right.$ and $\left.1000^{\circ} \mathrm{C}\right)$ in $\mathrm{N}_{2}: \mathrm{O}_{2}$ gas atmosphere.

After the oxidation process the results have shown a degradation of minority carrier lifetime $\tau_{\text {eff }}$ depending on the oxidation temperature. The investigations conducted in order to study the causes of this degradation have been realized by means of quasi-steady-state photoconductance (QSSPC) lifetime measurement system (model WCT-120 from Sinton Instrument) and using other investigation techniques, based on theoretical predictions of an analytical model.

\section{Results and discussion}

\subsection{Influence of high temperature oxidation on minority carrier lifetime}

Figure 1 represents the $\tau_{\text {eff }}$ versus temperature. We can see from this diagram that the minority carrier lifetime had drastically decreased as a function of the oxidation temperature, knowing that all samples had a minority carrier lifetime of $30-40 \mu$ s before the oxidation.

In order to understand the origin of this degradation, we have investigated the samples realized at the limit 


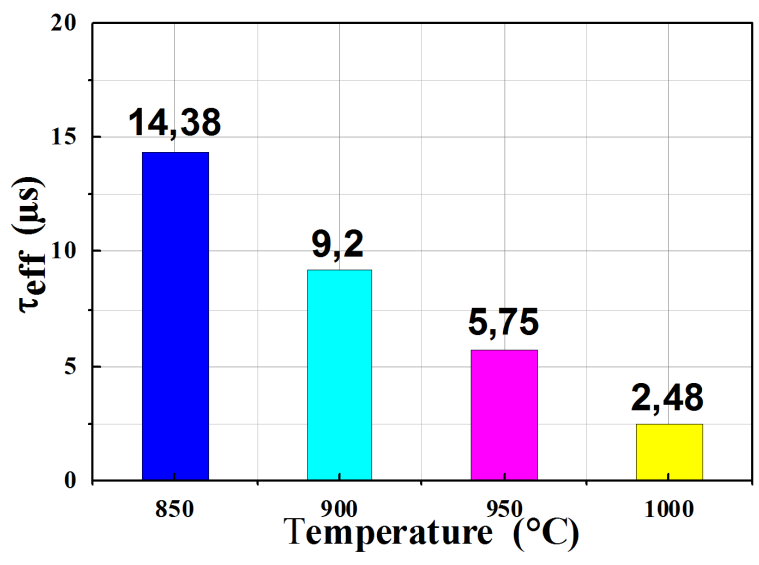

Fig. 1. Minority carrier lifetime $\tau_{\text {eff }}$ as function of oxidation temperature.

temperatures of $850{ }^{\circ} \mathrm{C}$ and $1000^{\circ} \mathrm{C}$. The passivation quality had been evaluated by extraction of the surface recombination velocity (SRV) value. It has been calculated from the fitting of experimental data to the $\mathrm{SRH}$ lifetime $\tau_{\mathrm{SRH}}$ model, according to the following equation $[9,10]$ :

$$
\begin{aligned}
& \tau_{\mathrm{SRH}}(\Delta n, T)= \\
& \frac{\tau_{n 0}\left(p_{0}+p_{1}+\Delta n\right)+\tau_{p 0}\left(n_{0}+n_{1}+\Delta n\right)}{\left(p_{0}+n_{0}+\Delta n\right)},
\end{aligned}
$$

where the electron and hole capture time constants $\tau_{n 0}$ and $\tau_{p 0}$ are related to the defect density $N_{t}$, the thermal velocity $v_{\mathrm{th}}$, and the electron and hole capture cross sections $\sigma_{n}$ and $\sigma_{p}$ via $\tau_{n 0}=\left(\sigma_{n} v_{\mathrm{th}} N_{t}\right)^{-1}$ and $\tau_{p 0}=\left(\sigma_{p} v_{\mathrm{th}} N_{t}\right)^{-1}$.

Figure 2 represents lifetime measurements and SRH fits before and after oxidation. The fit parameters before oxidation give an SRV $=850 \mathrm{~cm} \mathrm{~s}^{-1}$, however the SRV values have reached $40 \mathrm{~cm} \mathrm{~s}^{-1}$ after oxidation at both temperatures of $850^{\circ} \mathrm{C}$ and $1000^{\circ} \mathrm{C}$.

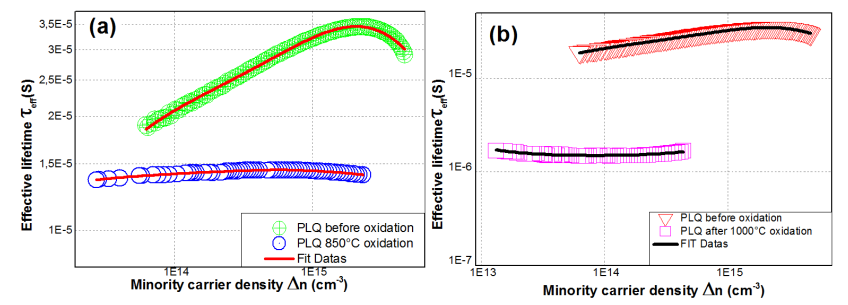

Fig. 2. Lifetime measurements (symbols) and SRH fits (solid lines) before and after oxidation process at (a) $850{ }^{\circ} \mathrm{C}$, (b) $1000^{\circ} \mathrm{C}$. The parameters used during fitting are given in Table I.

These values are in a good agreement with many works undertaken in the field of the passivation by a thin layer of $\mathrm{SiO}_{2}$ [11]. Thus, this value of SRV represents a net decrease in the surface recombination rate, and therefore it is a good indicator of surface passivation.
Thereby, it can be concluded that the minority carrier lifetime degradation after oxidation process is not due to the surface defects, but it is due to the bulk degradation.

The fitting of experimental data to the $\tau_{\mathrm{SRH}}$ model (Fig. 2) has allowed us to estimate the recombination center density $N_{\mathrm{r}}$, and the capture cross-sections of the electrons and holes. These values are reported in the table below. From the results shown in Table I, one can deduce that the oxidation temperature has generated defects in the bulk of the silicon substrate, causing an increasing of the density of recombination centers.

The determination of the capture cross section $\sigma_{n}$ and $\sigma_{p}$ after oxidation reveals that the values coincide perfectly with those related to the iron-boron pair (FeB) impurities, as reported by D. Walz et al. [12]. Therefore, we can assume that the degradation of the minority carrier lifetime under the oxidation is mainly due to the iron contamination. It seems that these impurities are initially in the form of iron precipitates. Then, under the temperature effect, the dissolution of iron precipitates generates interstitial iron, which bonds with boron and forms iron-boron pairs (FeB) [13], known to be active recombination centers.

TABLE I

Capture cross sections and the recombination center density, deduced from the fitting of SRH lifetime model to experimental data.

\begin{tabular}{c|c|c|c}
\hline \hline Description & $\sigma_{n}$ & $\sigma_{p}$ & $\begin{array}{c}N_{\mathrm{r}}\left[\mathrm{cm}^{-3}\right] \\
\approx[\mathrm{FeB}]\end{array}$ \\
\hline Samples before oxidation & - & - & $5 \times 10^{11}$ \\
Samples oxidized at $850^{\circ} \mathrm{C}$ & $3 \times 10^{-15}$ & $3 \times 10^{-14}$ & $1 \times 10^{13}$ \\
Samples oxidized at $1000^{\circ} \mathrm{C}$ & $3 \times 10^{-14}$ & $1 \times 10^{-15}$ & $2 \times 10^{14}$
\end{tabular}

\subsection{Iron investigation}

To confirm the previously mentioned assumption, we have carried out annealing of the wafers at $850^{\circ} \mathrm{C}$ and $1000{ }^{\circ} \mathrm{C}$ in $\mathrm{N}_{2}$ atmosphere. Then, in order to minimize surface recombination, the wafers were passivated with iodine-ethanol. This technique provides very low surface recombination velocities and hence we can assumed that $\tau_{\text {eff }} \approx \tau_{\text {bulk }}[14]$.

Bulk iron contamination was studied by flashing samples with maximum power flash of QSSPC (peak intensity of $25 \mathrm{~W} / \mathrm{cm}^{2}$ ), because the illumination methods are well-established and based on photodissociation of ironboron pairs. The dissociation behavior was measured using QSSPC decay method. The obtained results are depicted in Fig. 3. The lifetime was measured after each series of flashes and the time without illumination was too short for a measurable dissociation of the (FeB) pairs.

Figure $3 \mathrm{a}$ and $\mathrm{b}$, shows the influence of illumination on the minority carrier lifetime with a crossover point near $\Delta n=1 \times 10^{14} \mathrm{~cm}^{-3}$. The characteristic crossover point of the injection-level-dependent carrier lifetime curves, measured before and after optical dissociation, reveals 

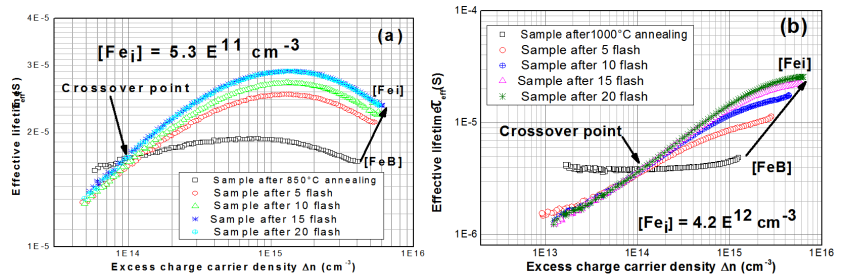

Fig. 3. Effect of light on the injection-dependent carrier lifetime, measured by means of the QSSPC technique on p-type silicon sample annealed at temperatures of (a) $850^{\circ} \mathrm{C}$ and (b) $1000^{\circ} \mathrm{C}$.

dissociation of $(\mathrm{FeB})$ pairs [15], as was reported in the previous studies of Macdonald et al., who have used the crossover point for the detection of iron contamination in silicon [16, 17]. More details are available elsewhere [17].

When the samples are under illumination, the (FeB) pairs are dissociated and the $\left[\mathrm{Fe}_{\mathrm{i}}\right]$ concentration rises to its maximum, with the increase of minority carrier lifetime, due to the neutrality of interstitial iron during illumination. Therefore, no Coulomb attraction exist between iron and boron [17]. This allows annihilation of recombination centers due to $(\mathrm{FeB})$ pairs. The calculation of interstitial iron in samples annealed at $850^{\circ} \mathrm{C}$ gives $\left[\mathrm{Fe}_{\mathrm{i}}\right]=5.3 \times 10^{11} \mathrm{~cm}^{-3}$, and in those annealed at $1000^{\circ} \mathrm{C}$, $\left[\mathrm{Fe}_{\mathrm{i}}\right]=4.2 \times 10^{12} \mathrm{~cm}^{-3}$. This difference in interstitial iron concentration can be explained by the correlation between the dissolution of the iron precipitates and the temperature effect.

We also will note that these values are different from those found in the simulation (see Table I), probably because the intensity of the illumination used is not sufficient for complete dissociation. In conclusion, it seems clear that the iron contamination is the main cause of minority carrier lifetime degradation after the thermal oxidation process.

\section{Conclusions}

In this paper we have shown that the surface passivation of silicon wafer using thermal oxidation can lead to the opposite effects, caused by bulk degradation. Hence, the aim of our study was to analyze the defects produced by high oxidation temperature. The undertaken investigation has shown that after oxidation, we got a low surface recombination velocity of $40 \mathrm{~cm} / \mathrm{s}$, thus proving the passivating effect of $\mathrm{SiO}_{2}$. Nevertheless, we have obtained a drastic decreasing in the minority carriers lifetime.

The calculation of $\sigma_{n}$ and $\sigma_{p}$ has allowed to conclude that the iron $(\mathrm{Fe})$ impurity is primarily responsible for the minority carrier lifetime degradation, due to the dissolution of the iron $(\mathrm{Fe})$ precipitates under the effect of high temperature, leading to the formation of boron-iron (FeB) pairs, which are well known for their high recombination activity. These results are confirmed by a fast and simple method for identifying interstitial Fe in borondoped silicon, via measurements of the so-called crossover point.

\section{References}

[1] Ç.Ş. Güçlü, A.F. Özdemir, A. Kökce, Ş. Altindal, Acta Phys. Pol. A 130, 325 (2016).

[2] Z. Zhuo, Y. Sannomiya, K. Goto, T. Yamada, H. Ohmi, H. Kakiuchi, K. Yasutake, Curr. Appl. Phys. 12, S57 (2012).

[3] Z. Jianhua, W. Aihua, M.-A. Green, Solar Energy Mater. Solar Cells 65, 429 (2001).

[4] S. Zhengrong, S.R. Wenham, J. Jingjia, in: 34th IEEE, Photovoltaic Specialists Conf., Philadelphia, USA 2009, p. 1922

[5] J. Knobloch, S.W. Glunz, D. Biro, W. Warta, E. Schaffer, W. Wettling, in: 25th IEEE Photovoltaic Specialists Conf., vol. 4, (1996), p. 405.

[6] G.A. Aberle, Crystalline Silicon Solar Cells: Advanced Surface Passivation and Analysis, Centre for Photovoltaic Engineering, University of New South Wales, Sydney 2004.

[7] J. Schmidt, M. Kerr, A. Cuevas, Sci. Technol. 16 164 (2001).

[8] T. Lauinger, J. Moschner, A-G. Aberle, R. Hezel, J. Vac. Sci. Technol. A 16, 530 (1998).

[9] D. Macdonald, A. Cuevas, Appl. Phys. Lett. 74, 1710 (1999)

[10] J.A. Hornbeck, J.R. Haynes, Phys. Rev. 97, 311 (1955).

[11] N. Ewen Grant, K.R. McIntosh, IEEE Electr. Dev. Lett. 31, 1002 (2010).

[12] D. Walz, J.-P. Joly, G. Kamarinos, Appl. Phys. A: Mater. Sci. Proc. 62, 345 (1996).

[13] D. Macdonald, A. Cuevas, J. Appl. Phys. 89, 7932 (2001).

[14] N. Khelifati, D. Bouhafs, A. Mebarek-Azzem, S.E.-H. Abaidia, B. Palahouane, Y. Kouhlane, Acta Phys. Pol. A 130, 188 (2016).

[15] S. Rein, Lifetime Spectroscopy: A Method of Defect Characterization in Silicon for Photovoltaic Applications, Springer, 2005.

[16] D. Macdonald, T. Roth, P.N.K. Deenapanray, Appl. Phys. Lett. 89, 142107 (2006).

[17] C. Möller, A. Laades, K. Lauer, Solid State Phenom. 205, 265 (2014) 